\title{
РАЗВИТИЕ ПОЗНАВАТЕЛЬНЫХ ПРОЦЕССОВ У СТУДЕНТОВ- МЕДИКОВ В ПРОЦЕССЕ ОСВОЕНИЯ КУРСА «ЛАТИНСКИЙ ЯЗЫК И ОСНОВЫ МЕДИЦИНСКОЙ ТЕРМИНОЛОГИИ»
}

\section{THE DEVELOPMENT OF COGNITIVE PROCESS AMONG MEDICAL STUDENTS MASTERING THE COURSE "LATIN LANGUAGE AND THE BASICS OF MEDICAL TERMINOLOGY"}

\section{Trubina \\ E. Ryabkova \\ U. Safarova}

Summary: The main goal of modern education is to prepare a competitive personality is on demand side of labor market. Systematic work with medical students, aimed at the development of cognitive processes, mnemonic abilities, to overcome the difficulties associated with memorization, contributes to the achievement of optimal learning outcomes, ensuring a lasting assimilation of knowledge. The continuous development of the intellectual potential of medical students is an integral part of the successful mastering of professional core competencies of higher education of the future doctor today.

Keywords: memory, mnemonic techniques, memorization productivity, assimilation of information, translation skills, Latin language.
Трубина Ирина Сергеевна

к.п.н., дочент, Приволжский исследовательский медицинский университет (г. Нижний Новгород)

trus@yandex.ru

Рябкова Елена Анатольевна

cm. nреподаватель, Приволжский исследовательский медицинский университет (2. Нижний Новгород)

elenadimitr@mail.ru

Сафарова Умида Алиаскаровна

К.филол.н., доцент, Самаркандский Государственный Медицинский Университет safarovaua@yandex.ru

Аннотация: Основной целью современного образования является подготовка конкурентоспособной личности, востребованной на рынке труда. Системная работа со студентами-медиками, направленная на развитие познавательных процессов, мнемических способностей, на преодоление трудностей, связанных с запоминанием, способствует достижению оптимальных результатов обучения, обеспечивая прочное усвоение знаний. Постоянное развитие интеллектуального потенциала студентов - медиков является неотъемлемой частью успешного овладения профессиональными компетенциями, составляющими основу высшего образования будущего врача сегодня.

Ключевые слова: память, мнемические приемы, продуктивность запоминания, усвоение информации, навыки перевода, латинский язык.
A ктуальность идеи непрерывного образования, образования не «на всю жизнь», а «через всю жизнь» и, соответственно, обновления информации, составляющей содержание обучения, а также педагогических технологий ее передачи детям и взрослым подчеркивается в современных исследованиях (6). Проблема развития интеллекта студентов - медиков является приоритетным направлением современного образования в пространстве медицинского вуза. Повышенные требования к моральным и интеллектуальным качествам специалистов, работающих в сфере здравоохранения, высокий темп развития высокотехнологичных направлений в медицине, постоянно растущий объем информации - те реалии, в которых предстоит осуществлять профессиональную деятельность будущему врачу. Познавательные компетенции относятся к группе компетенций, относящихся к деятельности человека. Так, в нормативных документах ФГОС 3++ отражены требования к результатам освоения программы специалитета по направлению «Лечебное дело». В результате освоения программы у выпускника медицинского вуза должны быть сформированы универсальные, общепрофессио- нальные и профессиональные компетенции, в числе которых отмечаются: «УК-1 - способен осуществлять поиск, критический анализ и синтез информации, применять системный подход для решения поставленных задач; УК-7. - способен управлять своим временем, выстраивать и реализовывать траекторию саморазвития на основе принципов образования в течение всей жизни; ОПК-5способен решать стандартные задачи профессиональной деятельности с использованием информационных, библиографических ресурсов, медико-биологической терминологии» (1). Поэтому продуктивное и репродуктивное познание и связанные с ним познавательные процессы, интеллектуальная деятельность, связанная с приемом, переработкой, выдачей информации, имеют огромное значение.

Объектом нашего исследования являются студенты первых курсов, обучающиеся в медицинском вузе. Опыт работы с первокурсниками в ПИМУ показывает, что студенты особенно начальных курсов по-разному адаптируются к университетской системе, имея различную степень развития познавательных процессов, уровень 
языковой подготовки. В связи с чем, в условиях интенсивного потока информации ряд студентов сталкиваются с различными трудностями, связанными с не усвоением полученных знаний. Таким образом, постановка целей, направленных на эффективность учебного процесса, на интеллектуальное саморазвитие, обучение, в основе которого лежит осознанный подход к получению знаний, владение методическими приемами и техниками, облегчающими учебный процесс, является определяющими ориентирами в организации учебной деятельности современного студента-медика.

Курс «Латинский язык и основы медицинской терминологии», изучаемый студентами на первом курсе, занимает особое место в системе языковых дисциплин. Заложение основ терминологической грамотности невозможно без овладения лексическим и грамматическим материалом, который включает в себя порядка 500-700 терминов. Без навыка перевода терминов невозможно накопление и дифференциация системообразующих лексических единиц, которые в будущем позволят студентам использовать их в профессиональном дискурсе. Все знания самого высокого порядка являются результатом интеграции знаний, получаемых с помощью познавательных психических процессов разного уровня сложности. Системный тип мышления, высокие показатели объема и избирательности внимания являются обязательными составляющими субъекта врачебной профессиональной деятельности. Их наличие для врача является значимым и важным, а начальная стадия профессионализации, совпадающая с началом обучения в вузе, является высоко сенситивным периодом к развитию познавательных процессов. При этом особенно востребованной во врачебной деятельности является память. Так, Б.А. Ясько отмечает важность мнемических способностей в структуре профессиональной компетентности врача: «Развитая оперативная память, её большой объем, быстрота и точность воспроизведения, помехоустойчивость являются основными характеристиками памяти и значимыми условиями успешности профессиональной деятельности врача» (8, с. 201).

Как отечественные, так и зарубежные ученые (С.П. Бочарова, Л.С. Выготский, П.И. Зинченко, Р. Кацки, Л.К. Латышева, А.Н. Леонтьев, Дж. Миллер, Р.К. Миньяр-Белоручева, В.И. Проворотова, Т.И. Скоробогатова Т.И. Тивьяеева и др.) в своих работах фиксируют память как одну из важных составляющих процесса формирования личности, соотносимую с организацией обучения, профессиональной деятельностью, представляющую собой комплекс процессов, с помощью которых человек воспринимает, запоминает, хранит и воспроизводит информацию. Память является процессом, обеспечивающим построение всестороннего образа мира, связывающим как цемент все строительные элементы психической мозаики в единую, полную жизни картину. (3, с.302)
В зависимости от аспекта функционирования существуют различные классификации видов памяти. Так, основываясь на классификации А.В. Сунцовой, С.В. Курдюковой, представляющих нейропсихологический подход к развитию памяти, приводится типология памяти по различным критериям. Так, с точки зрения длительности сохранения информации выделяется:

- кратковременная память (первичная, активная), которая имеет свойство хранить данные в течение относительно небольшого промежутка времени. Кратковременная память представляет собой один из психических процессов, которому свойственно ограниченное время хранения информации и ограниченное количество удерживаемых элементов. Отбор материала осуществляется через направленность внимания на определенные объекты. Независимо от цели запоминания, первично информация хранится в кратковременной памяти. В дальнейшем данные переходят на долговременное хранение, либо утрачивают свою актуальность и вытесняются. С помощью кратковременной информации перерабатывается большой объем информации: происходит отсев неиспользуемой информации и остается потенциально полезная;

- оперативная память - рассчитанная на хранение информации в течение определенного, заранее заданного срока, необходимого для выполнения некоего действия или операции. Срок хранения информации может колебаться от нескольких секунд до нескольких дней. Информация сохраняется в оперативной памяти в том случае, если она используется в текущий момент или может понадобиться в ближайшее время. Этот вид памяти является переходной от кратковременной к долговременной, так как включает в себя элементы обоих видов;

- долговременная память - способна хранить информацию в течение неограниченного срока вмещающий огромный объем знаний, умений, навыков. Долговременная память наиболее надежное хранилище информации и очень важна для изучения иностранных языков.

По характеру запоминаемого материала можно выделить:

- двигательную память - запоминание, воспроизведение разнообразных движений;

- эмоциональную память - память на переживания, чувства, эмоции. На эмоциональной памяти основана прочность запоминания материала - то, что у человека вызывает эмоции, запоминается легче и на более длительный срок.

- образную память, связанную с запоминанием и воспроизведением чувственных образов предметов и явлений, их свойств, отношений между 
ними. Образную память можно разделить по виду анализаторов, которые участвуют в запоминании: слуховую, зрительную, обонятельную, осязательную.

- вербальную или словесно-логическую - запоминанию информации предшествует понимание информации, установление логических связей. Большое значение имеет слово, мысль, логика. На использовании словесно-логической памяти строится усвоение знаний в процессе обучения.

В зависимости от того, какой анализатор принимает наибольшее участие в процессе запоминания выделяются следующие виды памяти: зрительную, слуховую, тактильную и т.д. Зрительная и слуховая память являются ведущими. Параллельное использование памяти различных модальностей создает оптимальные условия для запоминания материала.

По характеру целей мнестической деятельности выделяют произвольную и непроизвольную память. При непроизвольном запоминании объекты фиксируются в памяти без каких - либо усилий со стороны запоминающего. Непроизвольно может быть запомнен материал, который вызывает интерес, имеет большое значение или эмоционально окрашен. Произвольная память подразумевает наличие конкретной цели запоминания, прикладывая определенные волевые усилия. (7, с.13)

Таким образом, можно сделать вывод о том, что систематические знания возникают в результате специальной деятельности, при которой ставится задача запомнить и удержать соответствующий материал. Проведение направленной работы со студентами-медиками с использованием специальных методов развития объема памяти будущих врачей, предлагаемых современных педагогических, психолого-развивающих методик на занятиях по «Латинскому языку и основам медицинской терминологии включало в себя несколько этапов.

1 этап - ориентационный, основная цель которого сформировать направленность, готовность на саморазвитие, как нового уровня функционирования, на интенсификацию и повышение эффективности собственной интеллектуальной деятельности, осмысленное применение определенных техник, мнемических приемов, обеспечивающих прочное усвоение знаний для оптимального достижения результата обучения на материале курса «Латинский язык и основы медицинской терминологии». Основные задачи этого этапа:

- формирование убеждений в необходимости развития собственного интеллектуального потенциала в структуре будущей профессиональной деятельности, связанной с медициной;

- дать смысловую установку значимости, роли, места развития памяти в структуре формирования профессионально важных качеств, необходимых для профессионального становления;

- углубление представлений и систематизация собственных интеллектуальных ресурсов и возможностей их развития.

2 этап - преобразующий, на котором студентам был предложено изучение теоретических основ, связанных с проблемой памяти, ознакомление и овладение различными техниками, позволяющими качественно повысить процесс обучения. Основными задачами этого этапа стали:

- формирование системы знаний об общей организации механизмов памяти мозга, о возможности влияния на собственный мозг путем тренировки памяти;

- ознакомление с особенностями, связанными с психофизиологическими процессами функционирования памяти;

- овладением различными техниками, направленными на более продуктивное запоминание, воспроизведение информации.

Для овладения любым иностранным языком важны такие процессы как запоминание, воспроизведение, сохранение информации с целью дальнейшего опознания грамматических и лексических единиц. С практической точки зрения именно запоминание определяет полноту и точность сохранения и последующего воспроизведения материала, прочность и длительность его сохранения. В этой связи особое место было отведено применению мнемонических приемов - методов сохранения информации в памяти и обеспечения ее следами памяти, зацепками, которые ускоряют к ней доступ, адаптированных к курсу латинского языка. Мнемотехника основана на произвольной (целенаправленно организуемой) памяти, поэтому используется для запоминания мысленное упорядочивание запоминаемой информации и связывание её между собой с помощью различных приемов. Для расположения и связывания используются возможности мышления (особенного образного), воображения, внимания. В преподавании латинского языка целесообразно использование следующих методов языковых мнемотехник:

- метод звуковых ассоциаций: примером может послужить слово Tympanum - барабан, которое запоминается, если представить, как человек играет руками на барабане ритм: тум па - нум па. Ala (крыло) запоминается в словосочетании «летала птица».

- метод зрительных ассоциаций: запомнить слово carpus (запястье) можно представляя картину, что поймали карпа, но он вырывался из рук и укусил за запястье. Слово carpus созвучно со словом «карп». 
- метод акронимов (аббревиатур, буквенного кодирования) сфокусирован на создание смысловых фраз с акцентом на начальные буквы, может применяться для запоминания таких терминов как anterior (передний), posterior (задний), superior (верхний), inferior (нижний). По первым буквам каждого слова составляется акроним APSI. Фиксируем, что слова идут в логическом порядке по направлениям: передний, задний, верхний, нижний (для лучшего запоминания произносим направления и показываем их пальцем). Запоминаем акроним по созвучности со звуком чиха "апчхи". Также с помощью этого метода можно запомнить окончания существительных 3-го склонения мужского рода в именительном падеже, расставляя их в таком порядке, чтобы они составляли скороговорку - ex er es os or o.

- метод рифмы - один из распространенных способов запоминания слов, в котором могут быть использованы слова родного и изучаемого языка. Например, можно придумать маленькое стихотворение для запоминания слова genus: “Горько плачет мальчик Гена, он ударился коленом».

- метод сходств в написании слов и его значении позволяет сопоставить русский и латинский варианты написания и выявить закономерности. В словах Farfara - Мать-и-мачеха можно обнаружить по три буквы а. Для облегчения запоминания слова Jugum - возвышение можно обратить внимание на то, как пишется первая буква слова j, точка как бы возвышается над ней и быть знаком для запоминания термина возвышение.

- метод изучения этимологии слова способствует запоминанию терминов. Так, дословный перевод слова Нуррорhае (облепиха) с древнегреческого - "блестящая лошадь". Древние греки откармливали листьями облепихи ослабленных, больных лошадей. Лошади на таком рационе поправлялись, обретая округлость, шерсть у них становилась гладкой, лоснящейся, блестящей. Helianthus - подсолнечник происходит от греческих слов «helius» («солнце»; проводим ассоциацию с Гелиосом - древнегреческим богом солнца) и «anthemon» («цветок»).

- метод членения слова на составляющие особенно эффективен при запоминании наименований лекарственных растений, например в составе слова Millefolium - тысячелистник выделяем «mille» - тысяча и «folium» - лист. В составе слова мanubrium - рукоятка есть «manu» - часть слова «manus»- рука.

- Таким образом, правильная систематизация информации, осмысление, установление связей, структуры, принципа, закономерности построе- ния ассоциации, нетривиальные, яркие образы все это повышает продуктивность запоминания и усвоения информации и как следствие ведет к более эффективному процессу обучения.

Так же для более продуктивного запоминания лексического материала курса латинского языка студентам-первокурсникам было предложено изучение приложения Quizlet. Данный сервис представляет собой гибкий инструмент, позволяющий легко запоминать любую информацию, которая может быть представлена в виде карточек. Сервис включает в себя три вида подписок - студенческую, преподавательскую и бесплатную. Для работы необходимо создать список слов для заучивания. Слова могут быть отсортированы по алфавиту, либо по добавлению в набор. Приложение позволяет прослушивать слова на латинском и русском языках, что дает возможность не только обратить внимание на написание, но и услышать произношение с правильным ударением. В блоке изучения доступны следующие разделы: «Flashcards» («Карточки»), «Learn» («Заучивание»), «Speller» («Правописание») и «Test» («Тест»), Write («Письмо»). Функционал сервиса может загружать изображения и записывать собственный голос, а также тренировать правильное написание слов. Таким образом, использование аудиального и визуального способов репрезентации информации будут эффективными для студентов, имеющих различные ведущие репрезентативные системы.

Применение данного сервиса позволяет осуществлять контроль полученных знаний. Например, в режиме «Теst» («Тест») студент может проверить себя, увидеть результат своей работы. Система позволяет выбрать различные типы и объем вопросов, язык, на котором будет проводиться тестирование. Также функционал сервиса предлагает различные виды игр. Так, игра «Подбор» - предлагает соединить карточки с правильными ответами попарно. Игра «Гравитация» предполагает правильное написание слова для перехода на следующий уровень. В этом блоке возможно соревнование со своими друзьями, что делает обучение еще более интересным и увлекательным.

Таким образом, напоминая интеллектуальную игру, обучающий сервис Quizlet повышает у студентов продуктивность обучения, мотивацию к изучению предмета, благодаря своей доступности значительно экономит время на изучение дисциплины.

3 этап - практический, основной целью которого стало закрепление, реализация полученных знаний на практике. Этому этапу присуще сформированность установки на саморазвитие, ориентация на самосовершен- 
ствование.

Для более полной и активной работы с лексическим и грамматическим материалом, для отработки функции закрепления связей осуществлялась с помощью специально организованного материала, в котором центральное место принадлежит организации действий субъекта. Такие действия как группировка, соотнесение приводит к отбору и формированию определенных связей, повторение лишь условие реализации таких действий. Функцию закрепления связей осуществляет не повторение, а акт правильного воспроизведения объекта, соответствие воспроизведенного образа объекту запоминания. Для более активной и сложной работы с материалом были разработаны различные виды упражнений. Так, в разделе «клиническая терминология» для студентов предлагались такие задания, способствующие запоминанию терминоэлементов: определить общие терминоэлементы для каждой группы слов, сгруппировать и определить значение термина с общими терминоэлементами, распределить термины в соответствии с конечными терминоэлементами и т.д. Таким образом, применение сложных интеллектуальных способов преобразования материала, интенсивная и самостоятельная работа студентов с ним показала свою эффективность. Во время выполнения заданий у студентов-медиков с одной стороны, наблюдалась трансформация знаний и умений в личностный опыт, а с другой, происходило понимание, познание значения этого опыта в преодолении ситуативно обусловленных трудностей, связанных с изучением материала.

4 этап - рефлексивно-оценочный, итогом которого стало понимание того, что профессионально важные качества врача имеют системный характер. Постоянное интеллектуальное развитие - объективное требование профессии врачебной деятельности. Функциональная структура профессиональной деятельности является основанием для профессионально важных качеств, которые в свою очередь, тесно с вязаны с познавательными компетенциями, а именно с большим объемом оперативной и долговременной памяти. На этом этапе важно было инициировать выход студентов-медиков в рефлексивную позицию и произвести самоанализ собственной интеллектуальной деятельности, определить направления дальнейшего развития, обобщить полученный опыт с точки зрения применения его в других сферах деятельности.

Анализ эффективности специально проводимой работы со студентами первокурсниками позволяет сделать вывод, что знания закономерностей того, как память организует получаемую информацию, применение различных мнемических приемов в процессе обучения подходящих и эффективных лично для каждого из студентов позволяет правильным образом структурировать учебный материал, достигая тем самым высокого качества его усвоения при оптимальных затратах времени, способствует развитию ассоциативного мышления, внимательности, умения выявлять структуру и систематизировать изучаемый лингвистический материал, что, в конечном счете, приводит к более высокому уровню развития памяти и облегчает процесс обучения и на других предметах.

Подводя итог, отметим, что дисциплина «Латинский язык и основы медицинской терминологии» обладает значительным потенциалом не только в плане формирования профессиональной компетентности, но и способствует воздействию на интеллект и личность студентов путем развития таких значимых для обучения и личностного роста познавательных процессов как память, мышление, внимание. Деятельность врача относится к группе практических интеллектуальных видов труда. Поэтому очень важно поддержать и развить у студентов потребность в саморазвитии, само изменении, заинтересованности в знаниях - трансформациях, знании инструменте, которые в последствии позволят реализоваться в профессиональном поле будущей профессии. Именно студенчество - центральный период профессионального становления человека, личности в целом. Это возраст интенсивной и активной социализации, профессионального развития, время, когда приобретаются профессиональные знания, навыки и умения. Полученные исследователями школы Б.Г. Ананьева данные свидетельствуют о том, что «студенческий возраст - это пора сложнейшего структурирования интеллекта, что очень индивидуально и вариативно». (2, с.346) в студенческий период профессионального развития будущий врач не только приобретает профессиональные знания, навыки и умения, но и выбирает пути формирования профессионально важных качеств, необходимых для успешности будущей профессиональной деятельности. Особенно важным считаем ввести студентов не просто в смыслы, назначения, содержание будущей профессиональной деятельности, но и показать особенности ее освоения, дать установку на то, что личностное и профессиональное развитие сегодня - взаимодополняющие друг друга процессы, профессионализм врача соотносится с постоянным саморазвитием специалиста. Обеспечить превращение студента-медика из объекта педагогического воздействия в субъект образования, заинтересованного в самоизменении, обеспечивая тем самым прочную основу его как профессионала, способного к построению, изменению и развитию своей деятельности в будущем. 


\section{ЛИТЕРАТУРА}

1. http://fgosvo.ru/uploadfiles/ProjFG0SV03++/Spec3++/310501_C_3plus_12092019.pdf

2. Ананьев Б.Г. Педагогические приложения современной психологии / Б.Г. Ананьев //Хрестоматия по возрастной и педагогической психологии. Работы советских психологов периода 1946-1980гг./ под ред. И.И. Ильясова, В.Я. Ляудис. - М., 1981

3. Бордовская Н.В., Розум С.И. Психология и педагогика. - СПб.:Питер, 2011. - 624с.

4. Бочарова С.П. Психология памяти. Теория и практика для обучения и работы. 2-е изд., доп. Харьков: Изд-во «Гуманитарный Центр», 2016

5. Клацки Р. Память человека. Структуры и процессы. - М., 1978. - 319с.

6. Когнитивная психология в контексте проблем современного образования: монография / под ред. А.А. Вербицкого, Е.Б. Пучковой. - Москва.: МПгу. 2017. $-186 c$.

7. Сунцова А.В. Курдюкова С.В. Развиваем память с нейропсихологом. - М.:Генезис, 2019. - 64 с.

8. Ясько Б.А. Психология медицинского труда: личность врача в процессе профессионализации: дис. докт. псих. наук / Ясько Б.А. - Краснодар, 2004.- $436 c$.

\footnotetext{
๑ Трубина Ирина Сергеевна (trus@yandex.ru), Рябкова Елена Анатольевна (elenadimitr@mail.ru), Сафарова Умида Алиаскаровна (safarovaua@yandex.ru).

Журнал «Современная наука: актуальные проблемы теории и практики»
}

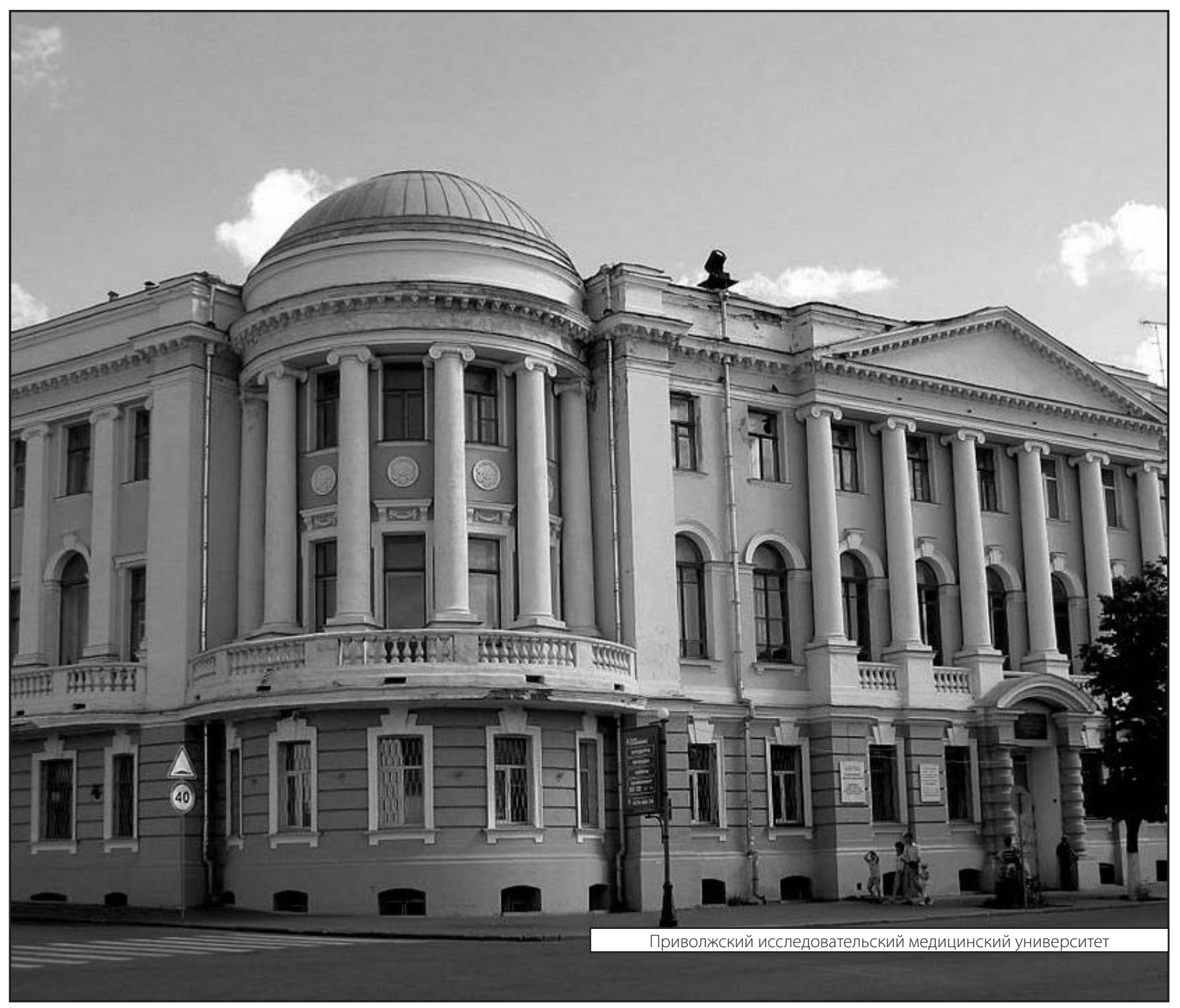

